Viability and resilience of small-scale fisheries through cooperative arrangements

\author{
P. Y. HARDY \\ CNRS MNHN \\ C. BENE \\ Institute of Development Studies \\ Sussex University (BRIGHTON - UK) \\ L. DOYEN \\ GREThA, CNRS, UMR 5113 \\ Université de Bordeaux \\ J. C. PEREAU \\ GREThA, CNRS, UMR 5113 \\ Université de Bordeaux \\ D. MILES \\ WorldFish Center, MALAYSIA \\ Coral Reef Studies, James Cook University, Australia \\ Cahiers du GREThA \\ $\mathrm{n}^{\circ}$ 2013-18 \\ September
}




\section{La coopération pour la viabilité et la résilience de petites pêcheries artisanales}

\section{Résumé}

Les petites pêcheries artisanales situées dans les iles du Pacifique sont actuellement confrontées à de fortes pressions écologiques, économiques, démographiques et sociales. En particulier, des stratégies de recherche de profit peuvent aggraver des vulnérabilités existantes, menacer la sécurité d'approvisionnement alimentaire, la pauvreté et la conservation de la biodiversité. Dans le cadre d'un modèle bio-économique couplant des dynamiques écologiques et socio-économiques, cet article propose une mesure quantitative de la résilience en lien avec la viabilité du système. Une attention particulière est portée sur l'importance des mécanismes de coopération pour la viabilité et la résilience bioéconomique. Dans le cas du système coutumier des îles Salomon appelé "wantok ", des illustrations numériques montrent quel est le gain de la coopération entre les pêcheurs en termes de subsistance, de profitabilité, de performances écologiques et de résilience face à des chocs.

Mots-clés : résilience, coopération, viabilité, temps de crise, pêcheries, wantok

Viability and resilience of small-scale fisheries through cooperative arrangements

\section{Abstract}

The small-scale fishery sector in many Pacific islands is facing increasing challenges in relation to resource availability, economic opportunity, demographic and social pressure. In particular, intensifying cash-oriented livelihood strategies can exacerbate existing vulnerabilities and threaten food security, poverty alleviation and resource conservation. In this paper we develop a bio-economic model and a quantitative measure of resilience to explore the interaction between socio-economic and ecological dynamics, and to analyse the potential role that cooperation and collective arrangements can play in this interaction to maintain the viability of the system. Based on the case of the customary system called wantok found in Solomon Islands, numerical examples are used to illustrate the gain that cooperation between fishers can bring in terms of subsistence, profitability, ecological performances as well as resilience to shock.

Keywords: resilience, cooperation, viability, crisis time, fisheries, wantok

Reference to this paper: HARDY P.H., BENE C., DOYEN L., PEREAU J. C., MILLS D. (2013) Viability and resilience of small-scale fisheries through cooperative arrangements, Cahiers du GREThA, n²013-18.

http://ideas.repec.org/p/grt/wpegrt/2013-18.html. 


\title{
Viability and resilience of small-scale fisheries through cooperative arrangements
}

\author{
Hardy P.-Y., Béné C. † Doyen L. , J.C. Pereau $\ddagger$ Mills D. ${ }^{\ddagger}$
}

July 2, 2013

\begin{abstract}
The small-scale fishery sector in many Pacific islands is facing increasing challenges in relation to resource availability, economic opportunity, demographic and social pressure. In particular, intensifying cash-oriented livelihood strategies can exacerbate existing vulnerabilities and threaten food security, poverty alleviation and resource conservation. In this paper we develop a bio-economic model and a quantitative measure of resilience to explore the interaction between socio-economic and ecological dynamics, and to analyse the potential role that cooperation and collective arrangements can play in this interaction to maintain the viability of the system. Based on the case of the customary system called wantok found in Solomon Islands, numerical examples are used to illustrate the gain that cooperation between fishers can bring in terms of subsistence, profitability, ecological performances as well as resilience to shock.
\end{abstract}

\section{Introduction}

Small-scale fisheries are facing increasing challenges induced by the amplitude and the pace of the changes that are taking place in both their economic and ecological 'worlds'. In many coastal developing countries, combined effects of pollution, climate change and overfishing affect marine habitats and reduce resources and diversity (Halpern et al., 2008; Mora, 2008). In some places, this situation is exacerbated by the rapid demographic transition that characterises the developing world (Sunderlin, 1994; Botsford et al., 1997). In

\footnotetext{
${ }^{*}$ CNRS-MNHN, 55 rue Buffon, 7005 Paris, France

${ }^{\dagger}$ Institute of Development Studies, Sussex University, Brighton BN1 9RE, UK

${ }^{\ddagger}$ GREThA, University Montesquieu Bordeaux IV, avenue Léon Duguit, Pessac, France

${ }^{\S}$ WorldFish Center, Penang, Malaysia, and C/o ARC CoE for Coral Reef Studies, James Cook University, Townsville, Australia
} 
particular, while the number of fishers may not grow any longer as rapidly as it has in the previous 50 years, global fishing effort is still increasing, mainly driven by economic forces and the demand from the growing (local and distant) urban population (Crossland and Philipson, 1993). This paper explores the issue of the viability of small-scale fisheries in this particular context. We are especially interested in considering the importance of the interaction between socio-economic and ecological dynamics, and in analysing the potential role that cooperation and collective arrangements between agents can play in this interaction to maintain the viability of the system.

The Pacific region is a very relevant 'prism' to observe and explore these issues. Most of the island countries in the region are still considered as poor countries and small-scale fisheries are an important (sometime the only) economic opportunity for many poor households, especially in the rural and remote parts of these islands (Kronen, 2004, 2007). The sector is therefore a keystone of the domestic economy. At the same time fish is also the main source of protein for the vast majority of the (urban and rural) population in the whole region (Yari, 2003/04; Molea and Vuki, 2008; Oreihaka and Ramohia, 1994). Unfortunately many of these islands are experiencing a rapid degradation of their marine resources (Dalzell et al., 1996; Aswani and Sabetian, 2009; Masu and Vave-Karamui, 2012). Fewer fish would therefore imply important food security problems for these countries (Weeratunge et al., 2011; Bell et al., 2009).

Fishers from this part of the world are currently experiencing other important socioeconomical changes. The ancient tradition of barter (Marshall, 1963; Sheppard and Walter, 2006) and gift economy (Feinberg, 1996) that had characterized these societies since centuries is being progressively eroded by the increasing need for cash imposed by the globalized economy (Dignan et al., 2004). Cash is in fact becoming a central element in the life of these people, even if subsistence economy is still prevalent, especially in rural areas (Schwarz et al., 2007; Kronen et al., 2008; Hardy et al., 2013).

Pacific small-scale fisheries are still managed through customary systems. These custom- 
ary systems do not refer only to community-based management rules that define how and where people can fish (Cinner, 2005; Faanunu, n.d.; Johannes, 1981). They also include social redistributive mechanisms between groups of fishers (including family and friends) that aim to ensure that each member of the group receives a minimum amount of fish irrespective of their personal catch. The underlying principle is one that ensures the food security amongst the different members of the community. In that sense this redistributive element shares some common features with the old concept of mutual aid described in Kropotkin (2009 [1904]), or Borkman (1999). These collaborative arrangements of redistribution are named in various ways around the Pacific region; the 'wantok' in Papua New Guinea and Solomon Islands, or the 'kerekere' in Fidji (Monsell-Davis, 1993; Gordon, 2011; Cinner, 2009). We propose to explore whether the establishment of these types of collaborative mechanisms among groups of fishers exploiting the same resource can be a critical element that contributes to create, or to maintain, the overall viability of the small-scale fishery system in a challenging environment where shocks and sudden changes in resource abundance are frequent.

To explore this hypothesis, we use the concept of resilience as understood in the socialecological literature. Many recent definitions of resilience have been proposed in different disciplines (Manyena, 2006; Bahadur et al., 2010). Most of them however share in common the basic idea that a resilient system is a system that is able to reduce/smooth the negative impacts of shocks and adapts when these changes affect parts of, or the whole system. Quantifying or measuring this ability to reduce impacts of perturbation is however methodologically difficult (Armitage et al., 2012; Frankenberger and Nelson, 2013; Béné et al., 2012). In our case, that is, under a dynamic framework, we follow Béné et al. (2001) and Martin (2005) who propose to link resilience to the concept of 'time of crisis'. Time of crisis is the time it takes for a dynamic system to come back to a viable state after a shock. In other words, the more resilient a system is, the shorter the time of crisis is expected to be. This approach is in fact relatively close to some of the earlier 'engineering' definitions of resilience as proposed by, e.g. Holling 1973 who defined resilience as the "ability of a system to bounce 
back or return to equilibrium following disturbance".

In the following section a bio-economic model of a small-scale fishery system is developed, which will enable us to estimate the time of crisis of the system through numerical simulations. Two scenarios will be considered in these simulations; the first scenario involves a community of four groups of fishers who do not cooperate with each other; the second scenario assumes that the members of these same groups are collaborating. The outcomes of these cooperative and non-cooperative strategies will be computed and compared in two different settings: with and without the effect of shocks. Elements of resilience theory will then be used to revisit these results and structure the discussion.

\section{The Solomon Islands case study}

Within the Pacific region, Solomon Islands were chosen for our research essentially due to three elements: (i) the country is characterized by one of the highest fish consumption rate of the region (35 kg/person/year (Bell et al., 2009)), emphasising the critical role that marine resources play for national food security; (ii) these islands have also one of the highest demographic rate in the Pacific region (between 2.3 and 2.8\% (CIA, 2001)), meaning that the current pressure on these marine resources is expected to continue to intensify in the future, rising some serious concern about their environmental sustainability; and (iii) Solomon Islands are one of the countries with the lowest Human Development Index of the region (143/186), highlighting the high prevalence of poverty across the whole population.

Within Solomon Islands, the Western province was used for our field work (see Figure (1)). There the small town of Gizo (on Gizo Island) where the fishing ground is shared by 4 communities of fishers was selected ${ }^{1}$. The cooperation between the four community is considered as an 'extended' wantok as in practice each community has its own constitutive wantok.

1. The information and data on the socio-economical context of this case study are derived from field work conducted by the first author of this article from May to August 2011 in the Gizo area, supplemented by a thorough review of the existing literature on Gizo market (Alec, 2005; Schwarz et al., 2007). 


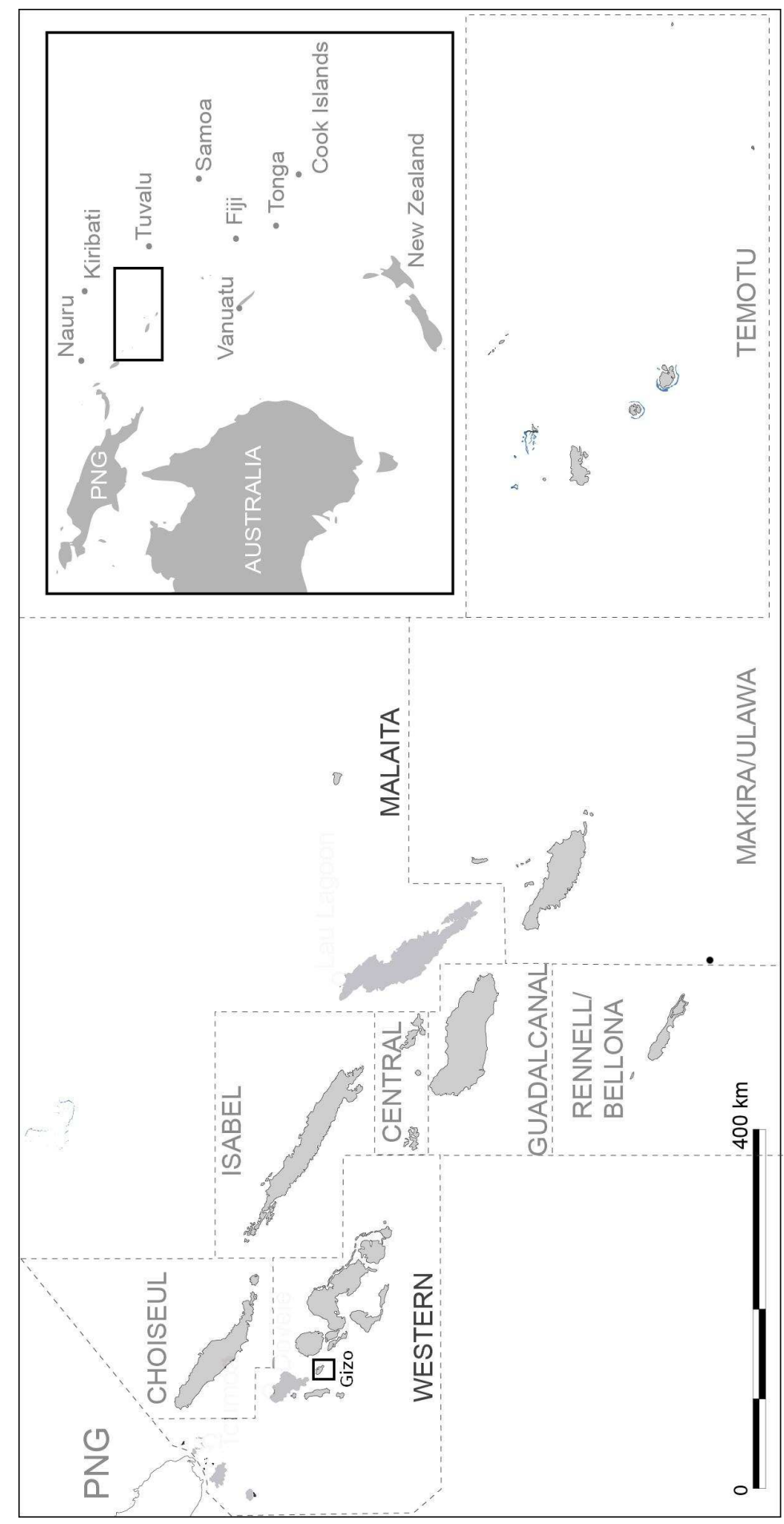

Figure 1: Solomon Islands

\section{The bio-economic model}

The dynamic bio-economic model is based on a renewable resource assumed to be exploited by heterogeneous agents who differ from each other by their operating (fishing) costs 
and catchability efficiency ${ }^{2}$. These agents' fishing strategies are assumed to be driven by cash optimality under subsistence constraints, following cooperative and non cooperative strategies. In our dynamic framework, both non cooperative and cooperative agents are assumed to be myopic with respect to the impact of their fishing effort on the stock dynamics. Hence cooperation is not considered as a way to internalize this stock dynamics but as a mean to concentrate the fishing effort into the hands of the most efficient agent(s) in order to ensure the fulfilment of the subsistence constraint for all agents.

\subsection{The dynamic model}

In discrete time the stock dynamics $B(t)$ exploited by the groups of fishers is characterised by an intrinsic growth $r$ and a carrying capacity $K$ through a logistic growth function:

$$
B(t+1)=B(t)\left(1+r\left(1-\frac{B(t)}{K}\right)-\sum_{i=1}^{N(t)} q_{i} e_{i}(t)\right)
$$

Using a Schaefer production function, the harvest $H_{i}(t)$ of each agent $i$ can be estimated as the combination of their fishing effort $e_{i}(t)$ and catchability $q_{i}$.

$$
H_{i}(t)=q_{i} e_{i}(t) B(t) \quad i=1, \ldots, N(t)
$$

Over the 10 years of the simulation, the number of fishers is assumed to increase according to the equation

$$
N(t+1)=N(t)(1+d)
$$

where $d$ stands for the demographic growth rate over time.

2. Catchability is the proportion of the stock that is removed by 1 unit of fishing effort over 1 unit of time 


\subsection{Agents' strategy: subsistence versus cash}

The different fishers (agents) are assumed to exploit the biomass $B(t)$ to cover their household's subsistence needs. These needs are noted $H_{\text {lim }}$. The subsistence need $H_{\text {lim }}$ is assumed to be similar for all agents and represents the minimum fish consumption required every week by individual households. The cash generated by each agent $i$ is the difference between the income derived from the remaining catch after consumption and costs of fishing efforts, as follows

$$
\pi_{i}(t)=p\left(\max \left(0, H_{i}(t)-H_{\lim }\right)\right)-c_{i}\left(e_{i}(t)\right)
$$

where the agents total fishing costs is represented by a quadratic cost function (following (Clark, 1990; Pereau and Doyen, 2012)). We have therefore:

$$
c_{i}(e)=c_{0}+c_{1, i} e+c_{2} e^{2}
$$

where the term $c_{0}$ represents fixed costs and $c_{1, i}$ is the variable unit costs, which differ between agents. The quadratic cost parameter $c_{2}$ can be related to travel costs (Sampson, 1992; Carr and Medelsohn, 2003) and social costs measured by the time not devoted to other social obligations (family, church) (Hanson and Ryan, 1998).

Agents are constituted by groups of homogeneous fishers (usually 5 fishers) from the same community and using the same fishing gear (see below)). Each agent is therefore characterized by a specific catchability efficiency $q i$ that reflects his own community's average catchability efficiency plus or minus a variation randomly assigned within a $20 \%$ range. All communities have different average catchability efficiency. Agents can therefore be ranked by decreasing efficiencies as follows:

$$
\frac{c_{1,1}}{q_{1}} \leq \frac{c_{1,2}}{q_{2}} \leq \cdots \leq \frac{c_{1, n}}{q_{n}}
$$


A strategy is said to be cooperative when the fishers of a community seek to maximize their aggregated revenues and simultaneously take into account the sum of the subsistence constraints for all members in the community. In other words, cooperative fishers would share both their subsistence constraints and cash maximization objective ${ }^{3}$. In contrast a non-cooperative strategy corresponds to a strategy where individual fishers factor in their own subsistence constraint while at the same time trying to maximize their own individual cash needs.

Note that the way the cooperative strategy is defined implies that it can be optimal for the most efficient fishers in the group to fish on the behalf of the least efficient fishers, to ensure that the $H_{\text {lim }}$ requirement is satisfied for all in the group. As will be discussed later, the success of this strategy will depend on the current status of the resource $B(t)$ and the degree of fishers' heterogeneity (in terms of catchability).

In sum the two strategies can be written as follows:

$$
\begin{aligned}
& \text { No cooperation: } \\
& \text { Cooperation : } \\
& \max _{e_{i}(t)} \pi_{i}(t) \\
& \left\{\begin{array}{l}
e_{i}(t) \geq 0 \\
H_{i}(t) \geq H_{\mathrm{lim}}
\end{array}\right. \\
& \max _{e_{1}(t), \ldots, e_{N(t)}(t)} \sum_{i=1}^{N(t)} \pi_{i}(t) \\
& \left\{\begin{array}{l}
e_{i}(t) \geq 0 \\
\sum_{i=1}^{N(t)} H_{i}(t) \geq N(t) H_{\mathrm{lim}}
\end{array}\right.
\end{aligned}
$$

In the case of non-cooperative strategy, fishers are assumed to adjust their fishing effort allocation to respond to the level of stock $B(t)$ as follows:

$$
e_{i}^{n c}(B(t))=\max \left(\frac{q_{i} B(t)-c_{1, i}}{c_{2}}, \frac{H_{\lim }}{q_{i} B(t)}\right)
$$

where nc denotes non cooperative strategy.

In the case of cooperative strategy (denoted by the subscript c), the allocation of fishing

3. The way cash and fish are redistributed among fishers in the cooperative framework is beyond the scope of the paper 
effort is

$$
e_{i}^{c}(B(t))=\max \left(\frac{q_{i} B(t)-c_{1, i}}{c_{2}}, \frac{1}{2 c_{2}}\left(\frac{2 N(t) c_{2} q_{i} H_{\mathrm{lim}}}{B(t) \delta(t)}+q_{i} \frac{\gamma(t)}{\delta(t)}-c_{1, i}\right)\right)
$$

with $\delta(t)=\sum_{i \in A(t)} q_{i}^{2}$ and $\gamma(t)=\sum_{i \in A(t)} q_{i} c_{1, i}$, and where $A(t)$ is the set of active fishers with a positive effort with $\left.i^{\star}(t)=\max \left(i, e_{i}^{c}(B(t))\right)>0\right)$ :

$$
A(t)=\left\{i \in\left(1, . ., i^{\star}(t)\right), q_{i} B(t)\left(\frac{2 c_{2} N(t) H_{\lim }+\sum_{j=1}^{i^{\star}(t)} c_{1, j} q_{j}}{\sum_{j=1}^{i^{\star}(t)} q_{j}^{2}}\right)-c_{1, i} \geq 0\right\}
$$

The mathematical proofs of these expressions are provided in Appendix 8.1.

\subsection{The resilience index}

The modelling analysis is completed by the computation of a resilience index. Following Béné et al. (2001) and Martin (2005), this resilience index is based on the calculation of system's 'time of crisis', that is, the time it takes for a system to come back to a viable configuration after a shock. In our case, viable configurations correspond to situations where the subsistence constraint defined by the threshold $H_{\text {lim }}$ is satisfied (i.e. food security is secured for all members of the community). In the non-cooperative case, the crisis time is given by:

$$
\operatorname{Crisis}^{n c}\left(B_{0}\right)=\sum_{t=t_{0}}^{T} \mathbf{1}^{n c}(t) \quad \text { with } \quad \mathbf{1}^{n c}(t)=\left\{\begin{array}{cc}
0 & \text { if } \quad H_{i}(t)>H_{\lim } \\
1 & \text { otherwise }
\end{array} \forall i\right.
$$

In the cooperative case, the crisis time is given by:

$$
\operatorname{Crisis}^{c}\left(B_{0}\right)=\sum_{t=t_{0}}^{T} \mathbf{1}^{c}(t) \quad \text { with } \quad \mathbf{1}^{c}(t)=\left\{\begin{array}{cc}
0 & \text { if } \sum_{i=1}^{N(t)} H_{i}(t)>N(t) H_{\mathrm{lim}} \\
1 & \text { otherwise }
\end{array}\right.
$$

In both cases, the resilience index is defined as the inverse of the time of crisis function 
(Deffuant and Gilbert, 2011):

$$
\operatorname{Res}\left(B_{0}\right)=\frac{1}{1+\operatorname{Crisis}\left(B_{0}\right)}
$$

As such our resilience index varies between 0 and 1 . Values close to 1 indicate systems with strong resilience (i.e. situations where a system can return to food security condition relatively rapidly), while values close to 0 indicate cases where a system has difficulties to return to a viable condition after a crisis. In particular resilience equals 0 when food insecurity crisis becomes permanent (infinite crisis time).

\subsection{Calibration of the model}

All simulations are based on a weekly time unit. The simulations are run over a 10-year period, assumed to correspond to 2011-2021 ${ }^{4}$. A single marine resource stock is considered. The initial biomass is assumed to be equal to $534 \mathrm{~kg} / \mathrm{ha}$ (Green et al., 2006), with an ecosystem carrying capacity of $5000 \mathrm{~kg} / \mathrm{ha}$ (which corresponds to the 'high biomass' category referred to in Green et al. (2006)) and an intrinsic growth rate of 0.0415 (Kramer, 2007). ${ }^{5}$

Four groups of fishers operate from the town of Gizo. The first group is the 'foreign' Melanesian from Malaita island (around 15 fishers in total) who fish using gillnets. The second group includes Micronesian individuals (around 70 fishers in total) who fish using spear-guns. The last two groups belong to the local permanent Melanesian community originating from Vella Lavella and Ranonga islands. The first of those two groups (about 45 fishers in total) fish during both day and night using hooks and lines, while the second group (around 30 fishers in total) fish only during day time, also with hooks and lines. In total the whole fishing community includes about 160 fishers who exploit the Gizo's reefs on a weekly basis. This corresponds to 16 big families (on average 10 fishers per family). Assuming two agents in average per family and four families in average per community, this means that an

4. Most of the field observations were collected in 2011.

5. The biomass is expressed in $\mathrm{kg}$ so the values from Green et al. (2006) are mutiplied by the areas shown in Table 3 in Appendix 8.2. 
equivalent of 32 agents operated in the Gizo area with $N b_{k}(t)$, the average number of agent per community $(k \in\{1,2,3,4\})$.

In small towns like Gizo, the average fish consumption per household was estimated to be around $45 \mathrm{~kg}$ per year (Bell et al., 2009) ${ }^{6}$. Fish market price remains relatively constant over the year, around 8.5 \$ Solomon dollars (SB) per kilo (P.-Y. Hardy, pers. observation, 2011). The quadratic cost of engaging in fishing activities is assumed to be the same for all fishers, i.e. $\forall i \quad c_{2}=2.2 \$ \mathrm{SB}$. The calilbration of $c_{2}$ is given is appendix 8.2. All fishers purchase fishing gear and petrol in Gizo town and face therefore the same variable costs. Empirical data suggests that these variable costs $c_{1, i}$ are around $21 \$ \mathrm{SB} \forall i$ (see Appendix $8.2)$.

The catchability parametrization specific to each agent is computed using the value of the average catch per hour per fisher of the community (community average productivity) plus or minus an individual variation randomly assigned within a $20 \%$ range. The spear gun users' productivity (group 2) with $5.8 \mathrm{~kg} / \mathrm{h} /$ fisher given in Sabetian (2010) is taken as the reference value. Gillett (2010) reports values of the same range (3 kg/h/fisher). The same report also estimates catchability values for the hook-liners $(1.9 \mathrm{~kg} / \mathrm{h} /$ fisher $)$ and the gillnetters $(15 \mathrm{~kg} / \mathrm{h} /$ fisher) for all the pacific region. Gizo area is probably characterized by slightly different values. In particular, based on our field observations, the productivity of the liners is from $0.45 \%$ (group 4) to $0.75 \%$ (group 3) higher than the productivity of the speargun fishers whereas the netters (group 1) fish three times more in the same time. The productivity expressed in $\mathrm{kg} / \mathrm{h} /$ fisher is multiplied by the number of agents and divided by the biomass in $\mathrm{kg}$ to obtain the catchability parameters (in $1 / \mathrm{h}$ ):

\footnotetext{
6. This is equivalent to $22.5 \mathrm{Kg} /$ agent/week since the average number of fisher per agent is 5 and the number of people in a fisher's household is 5.2 (National Statistic Office, 1999)
} 


\begin{tabular}{|c|cccc|}
\hline & Net & Spear & Line $(1 / 2$ day) & Line (day $/$ night) \\
\hline$N b_{k}\left(t_{0}\right)$ & 3 & 14 & 9 & 6 \\
\hline $\bar{q}_{k}$ & 0.000283 & 0.000094 & 0.000070 & 0.000042 \\
\hline
\end{tabular}

Table 1: The number of agent per community and their relative average catchability parameter

\section{Results}

Figure 2 displays the trajectories of the exploited resource $B(t)$, the average fishing efforts of each community (or group) $e(t)_{k} / N b_{k}(t)$, the average subsistence level $H(t) / N b(t)$ and average cash-income derived from fishing $\pi(t) / N(t)$ under the non-collaborative (Black curves) and collaborative (light blue curves) strategies. Figure 3 shows the similar trajectories when the system is affected by a significant shock . This shock corresponds to a sudden $50 \%$ drop in the biomass occurring after 3.5 years (within the 10 years of the simulation). In both cases (with and without shock), the simulations are run using the similar 2005 resource data and the socio-economic parameters as estimated in 2011. Figures 4 displays the resilience of the system under the $50 \%$ shock as a function of different levels of initial biomass (X-axis).

Even without the impact of any shock (Figure 2), the simulations already shows the beneficial effect of the collaboration between the fishers (that is, when they adopt the wantok rules). Without collaboration, the four groups of fishers are all fishing to ensure their individual subsistence (Fig.2, diagramme (b) black curves). The combined effect of their fishing pressure on the resource (diagramme (a) black curve) leads the resource-base $B(t)$ to slowly decline, forcing them to fish more intensively, in line with the race for fish described in the Tragedy of the Commons narrative. Eventually the fishing efforts of the four groups increase exponentially as the resource $B(t)$ collapses (just after 8 years). In the last few months before the collapse, the fishers were just able to maintain their subsistence (diagramme (c) black curve) at the food security threshold level $H_{\lim }$ (shown in red on the figure). Their cash had gone negative very quickly (diagramme (d)).

In sharp contrast with the scenario above, the collaborative fishing community manages 


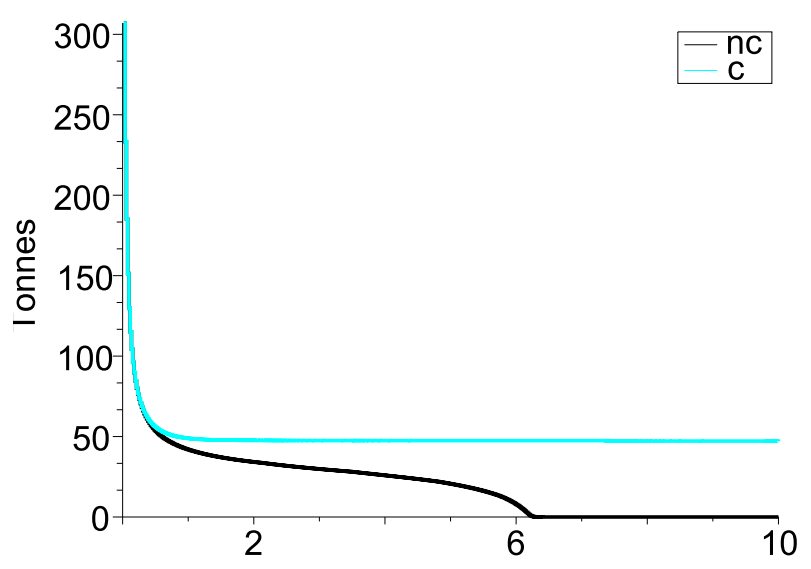

(a)

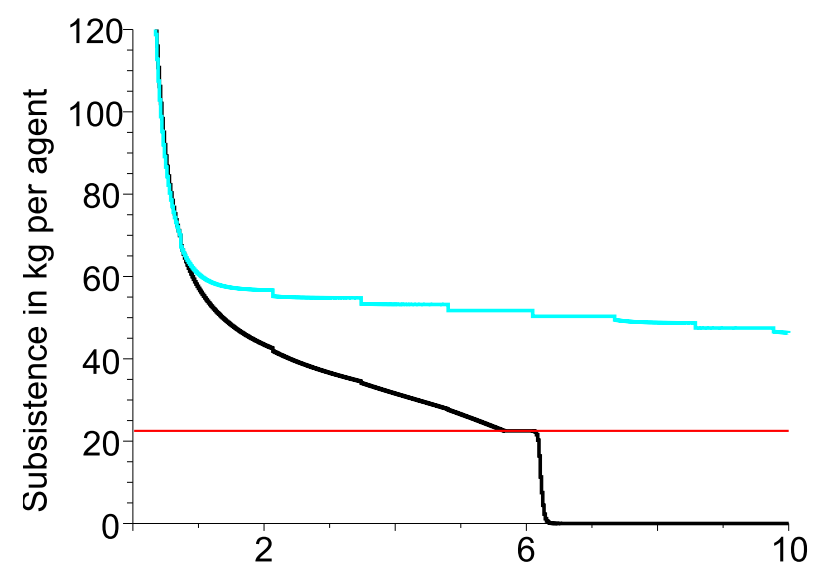

(c)
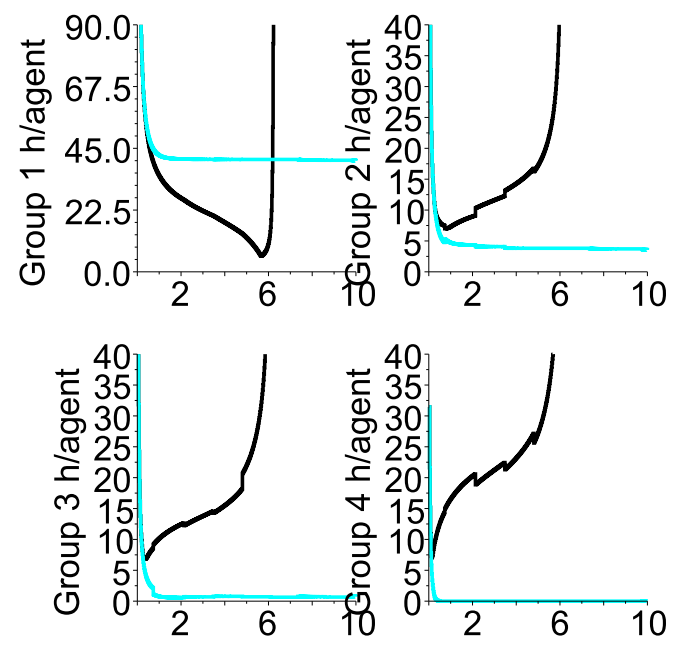

(b)

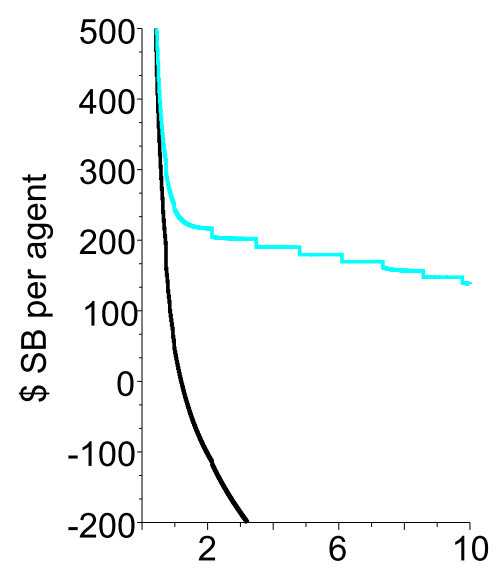

(d)

Figure 2: Cooperation vs non cooperation. Trajectories of biomass $B(t)$, community (or group) efforts $e_{k}(t)$, subsistence $H_{i}(t)$ and cash $\pi_{i}(t)$ in the case of cooperation ('c' in blue) and non cooperation ('nc' in black).

to maintain the resource $B(t)$ at a stable level (Fig.2, diagramme (a) light blue curve) and the aggregated subsistence level well above the food security threshold of $22.5 \mathrm{~kg} /$ week/agent ${ }^{6}$ (diagramme (c)). Similarly the cash income decreases slowly but remains positive ${ }^{7}$. This capacity of the community members to maintain their food security above the threshold

7. The slow decrease in both subsistence and cash-income indicators (while the resource level remains constant) is the consequence of the growth in population and the subsequent increase in number of fishers over the 10 years of the simulation. 


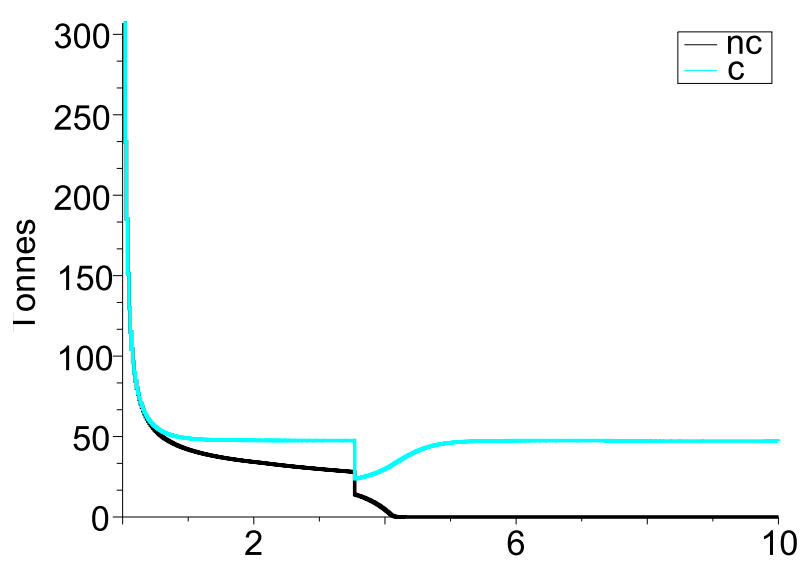

(a)

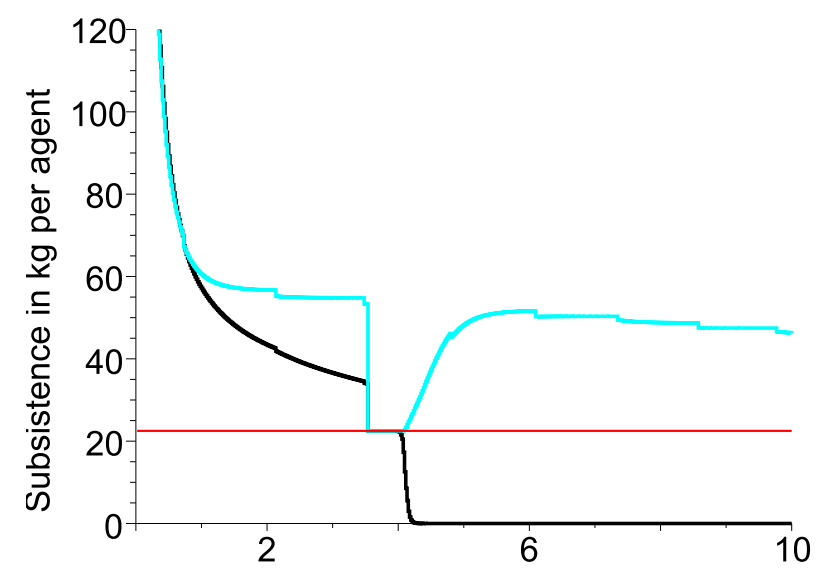

(c)
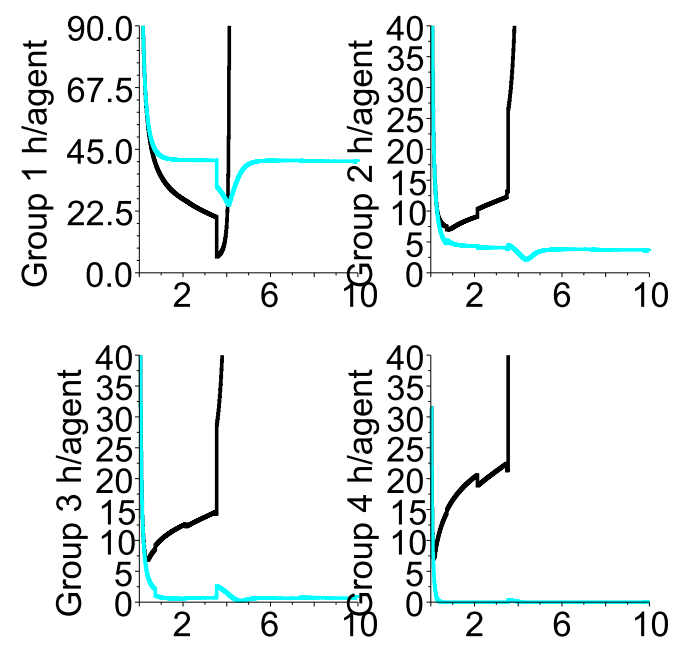

(b)

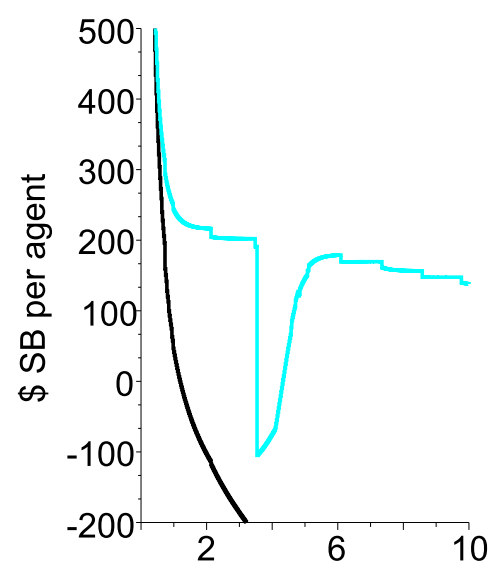

(d)

Figure 3: Cooperation vs non cooperation with a $50 \%$ shock in the biomass occurring after 3.5 year. Trajectories of biomass $B(t)$, community (or group) efforts $e_{k}(t)$, subsistence $H_{i}(t)$ and cash $\pi_{i}(t)$ in the case of cooperation ('c' in blue) and non cooperation ('nc' in black) .

$H_{\lim }$ is the result of the collaboration between the four different groups. As shown in the diagramme (b) light blue curve, the fishers of group 1 (the 15 individuals fishing with nets) are the only ones who continue fishing fully, while the other groups reduce drastically their activities (group 2 -speargun fishers- and group 3 -day and night hook-liners) or even stop fishing (group 4 -day hook-liners). Because they are very efficient fishers from group 1 are able to catch enough fish to feed the whole community and still maintain positive the 


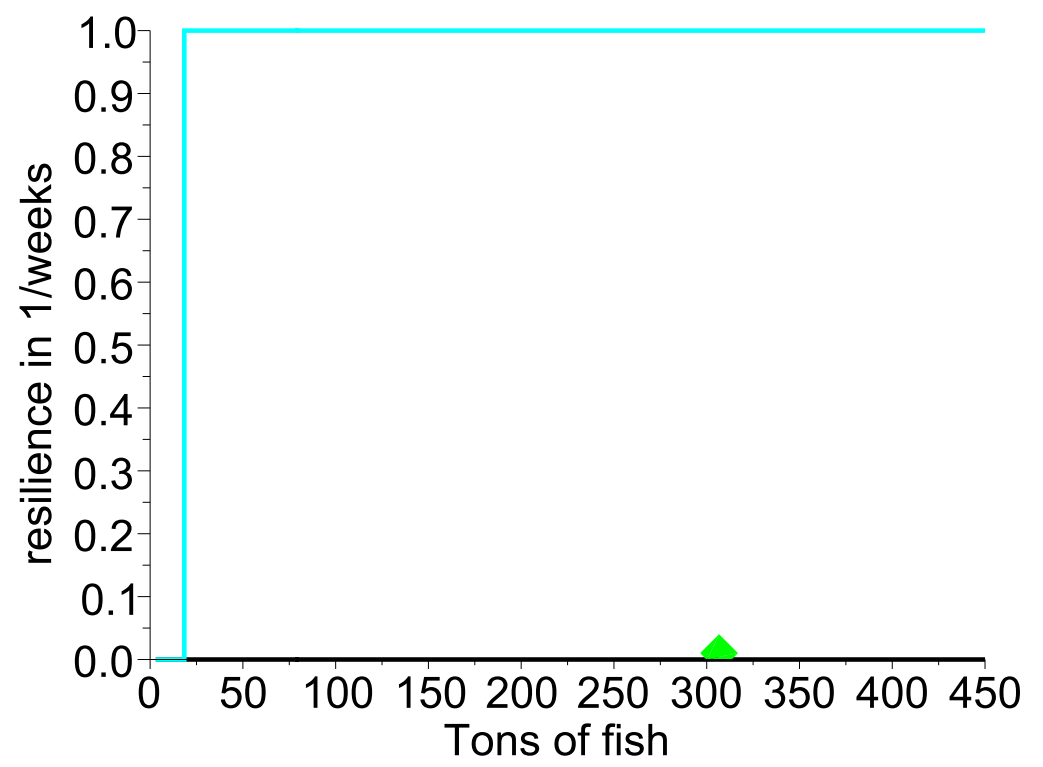

Figure 4: Resilience index: Comparison of resilience index $\operatorname{Res}(B)$ under cooperation ' $\mathrm{C}$ ' (blue) and non cooperation 'nc' strategies (black). Initial biomass $B\left(t_{0}\right)$ as estinmated in 2005 indicated by the green triangle.

aggregated cash-income for the whole community.

The scenario with the shock illustrates further the benefits of the cooperative strategy (Figure ??). Under the effect of the shock the non-cooperative fishing community crumples very rapidly. The resource-base is unable to recover from the initial $50 \%$ shock. The fishers in an attempt to maintain their subsistence at the level of the food security threshold $H_{\text {lim }}$, increase drastically their fishing effort (Fig.2, diagramme (b) black curves), leading to the collapse of the stock within few months (diagramme (c) black curve). Simultaneously, the fishers subsistence level passes below the threshold $H_{\text {lim }}$, indicating a food security crisis.

The case with cooperative strategy (light blue curves) shows a totally different outcome. As the shock hits the resource, the level of biomass $B(t)$ is reduced by $50 \%$. However in contrast with the non-cooperative situation, the resource bounces back relatively rapidly to the level where it was before the shock. The food security of the whole community is at stake for approximately one year during which the households subsistence is just maintained at the threshold level $H_{\mathrm{lim}}$. Fishers from groups 1 and 2 reduced their activities for few weeks 
while fishers from group 3 and 4 increased (marginally) theirs (diagramme (b)). They then stop when fishers from group 1 and 2 return to a level of activity comparable to the one they had prior to the shock. Both subsistence and cash-income indicators bounce back to their prior-shock trajectories.

Figure 4 shows the resilience index computed for both non-cooperative (black curve) and cooperative fishers (light blue curve) as a function of the initial biomass $B(0)$ for a $50 \%$ shock in the biomass. The curves confirm the great benefit of cooperative strategies. While the resilience index of non-cooperative fishers remain systematically at zero (suggesting that non-cooperative strategies provide the system with no resilience at all), the resilience index of cooperative fishers shows that for a large range of initial biomass the cooperative strategies offer the strong resilience property to the system. In particular as soon as the initial biomass $B(0)$ is above a specific threshold (let's note it $B^{\sharp}$ ) the resilience of the system is equal to 1 , meaning that irrespective of the biomass level, the system will always be able to avoid crisis.

\section{Discussion}

\subsection{Key-findings}

According to Oru (2011) or Russell (1948.), the local economy in Solomon Islands is an economy of social values rather than market ones. White (1991); Oliver (1989); Hviding (1996) have shown how intricate the production factors are, and how complex the economy that leads a community to sustain itself is. In our case, the bio-economic model purposively does simplify this complex reality and ignore other goods than fish. The model also does not include individual fishers per se but groups of fishers (aggregated into agents). The outputs cannot therefore be strictly compared with the empirical socio-economic situation. All the main components of the model, however, were calibrated using Solomon Islands data and the general trends observed through the model simulations can certainly be paralleled with what fishers operating in the fishery currently experience in their real life. As such the 
model provides reasonably realistic insights into the inter-related dynamics of biodiversity conservation, poverty alleviation and food security. A series of initial key-points emerge:

Cooperation helps maintaining ecological sustainability In both scenarios (with or without shocks) the numerical simulations indicate that biomass level maintained under the wantok system is always superior or equal to the biomass under non-cooperation. In effect, in both scenarios, the biomass under the wantok system stabilizes rapidly around 50 tons or 8.7 tones per $\mathrm{km}^{2}$ (except just after the shock where it is reduced by $50 \%$ ), while it continuously decreases and eventually collapses under the non-cooperative system. It seems therefore that cooperation helps promote marine resource sustainability.

Cooperation secures food security The numerical simulations also indicate that with or without shocks, fishers operating under the wantok system bring back home an aggregated catch which is always larger than non-cooperative fishers. This catch is then shared and redistributed amongst the community members, which guaranties a subsistence level well above the minimum food security threshold for everyone. In other words, the wantok system helps secure more catches and subsequently guarantees the food security of the whole community.

Even during the crisis period (following the shock) the cooperative community was able to maintain its subsistence level at the minimum food security threshold. The resilience analysis shows that this household subsistence condition can be satisfied at all time even in the case of severe shocks- provided that the resource-base started above a critical biomass level $B^{\sharp}$.

Cooperation is better for cash viability Although no specific condition was imposed in the bio-economic model on this dimension, the simulations indicate that the cash income generated by fishers operating under the wantok system is always superior or equal to the cash income derived under non-cooperation, at any time. In fact in both scenarios, the 
cash under the wantok system remains positive (except during a short period following the shock), while it very rapidly plummeted below zero under the non-cooperative system. In that sense, cooperation seems also to promote cash viability.

Cooperation strengthens resilience The model highlights the critical role that the wantok system plays in building the systems resilience. This happens in four distinct, but inter-related, manners.

First the wantok sytem prevents the system from collapsing. This is illustrated through the analysis of the non-cooperative arrangement, where the simulations show how the effect of the shock on the resource-base leads the whole system to collapse very rapidly (within months of the shock), as a combined result of the struggle of the community members to maintain their food security and the inability of the resource-base to sustain this extra pressure in addition to the effect of the $\operatorname{shock}^{8}$. In comparison, the system under extended wantok did not collapse.

Second, not only did the extended wantok prevents the system from collapsing, but it in fact enabled the different components of that system to return to their initial (pre-shock) state. This second result was not necessarily evident, even in the light of the first finding above. Indeed one could easily imagine that following the severe shock on the resourcebase the system re-establishes itself at a different, lower, level. This is not the case. The simulations show clearly that the different components of the system (that is, the resourcebase, fishing effort, income, and subsistence) were able to return to the trajectories/states they were following before the shock occurred.

Third, even during the crisis period that followed the shock, the fishers were able to maintain the subsistence of the entire community at the minimum food security threshold. This ability to preserve a critical function of the system was achieved by a change in the fishing strategy: fishers from the group 3 and 4 started to fish again for a short period of time,

\footnotetext{
8. Complementary analyses (not shown here) indicate that in the same conditions a resource affected by a similar shock but exempt of any fishing pressure is able to bounce back to its original level.
} 
while at the same time fishers from group 1 and 2 reduced their fishing effort. This strategy (which can be considered as a coping strategy at the community level) is the evidence of the ability of the fishers to adjust and modify their fishing behaviour under the wantok system in an attempt to protect their food security.

The three mechanisms above are in line with the first two dimensions of resilience as defined by Berkes et al, namely: (i) the amount of change that a system can undergo and still retain its function and structure; and (ii) the degree to which the system is capable of self-organization (Berkes et al. 2003, p.13). The third dimension of resilience is (iii) the ability to build and increase the capacity for learning, adapting, and where necessary transforming. In our case this capacity to adapt is facilitated by the wantok system itself. As shown by the model, this is the adoption of the wantok system in the first place that allows the fishers to adjust their fishing strategy and sustain their food security following the shock on the resource. As such the wantok system is contributing to this third dimension of resilience.

In addition to the above, another finding is worth emphasizing in relation to this discussion on resilience: the fact that the analysis also reveals the existence of potential tipping points. In the resilience literature these tipping points are particular thresholds which mark a fundamental, structural, change in the dynamics of a system (Scheffer, 2011, 2009). In our case, the critical biomass level $B^{\sharp}$ is clearly one of these tipping points. Below this threshold, the fishery is structurally unable to resist a shock of the magnitude considered in our example $^{9}$. In particular as shown in Figure 4, even if they are engaging actively in wantok arrangement the fishers will not be able to maintain the subsistence of the community at the minimum level to ensure food security if the resource-base started below this minimum threshold at all time.

In contrast, the same communitys subsistence condition will be satisfied at all time, if the resource has started above this threshold $B^{\sharp}$ (provided that the fishers engaged in wantok

9. Complementary analysis (not shown here) indicates that the critical biomass level $B^{\sharp}$ depends on the intensity of the shock. 
arrangements).

Finally it is interesting to note that two other recent studies also mentioned resilience in relation to the wantok system. One is Handmer and Choong (2009), who, in the macroeconomic context of Pacific islands, argue that the intersection between the wantok system and localized transnational capital "provides for a kind of resilience that is rarely talked about". The other is Gordon (2011) who consider that the "wantok system in this instance is resilient and a useful safety net for people when faced with natural and man-made disasters.". In these two cases, the resilience of the wantok system itself (Gordon, 2011) or the resilience it provides to the rest of the socio-economy (Handmer and Choong, 2009) acts as the mechanism that strengthens the overall capacity of individuals and Solomon Islands' society to respond and adapt to the challenging context that they face. In our case, the use of the concept of resilience is more specifically focused on one particular, but critical, function of the system, that is, food security. We also did not use the concept of resilience as a metaphor as Handmer and Choong (2009) and Gordon (2011) did, but instead as an indicator to quantity the ability of the community to maintain their level of food security in the aftermath of a severe shock. The resilience we are measuring is therefore of social nature, and depends on the ability of the community to adapt and adjust their fishing strategy in the context of a cultural institution, i.e. the wantok. But the analysis also showed that this social resilience is intimately linked to another -ecological- resilience, which is the ability of the resource-base to bounce back after the shock. In essence this illustrates the point now made by an increasing number of scholars who recognise the importance not to consider ecological or social resilience separately but instead to try to integrate both the social and ecological mechanisms of resilience into one single combined concept, that of social-ecological resilience (Armitage et al., 2012).

Is the wantok the solution? In Solomon Islands, the coral fish resource is currently showing growing sign of over-exploitation in some places, in particular close to urban centers 
(Sadovy, 2005). The Gizo reefs already show a consistent decrease of biomass and an increase in the number of fishers despite a very spread area with substantial resources (Alec, 2005).

Dalzell and Adams (1996) described the problem this way: there is just not enough fish and so not enough fish landed to feed everyone. In that context, the wider adoption of the wantok constitutes a crucial option for the system's resilience and so represents an essential driver for the Millennium Development Goals application. Indeed a long-term viable smallscale fishery sector is essential in a country where agriculture (Gibson and Brown, 2006; Browne and Scott, 1990) and other sectors (LaFranchi, 1999) are hardly developed, and where the national food security dependent so much on marine resources (Crossland and Philipson, 1993). The model presented in this paper suggests that the adoption of the equivalent of an extented wantok within the four communities of Gizo could drive the local socio-economical system toward a more sustainable and more resilient future. The model was calibrated in this particular context, but it is conceivable that its generalization is possible in the rest of Solomon Islands or even other parts of the western Pacific region where similar collective customary systems are still prevalent.

Would an extended wantok system work? Generalizing the application of the wantok system is not however without raising a certain number of questions. First: can the wantok be extended, and in particular would it easily be accepted among different societies and cultures? Second: what would be the social impact of a system where the best fishers in a community fish for the worst ones?

The full answer to these complex questions is beyond the scope of this paper, but some element of response can certainly be put forward. First, there is already a strong sense of collaboration and cooperation amongst fishers in Solomon Islands and more generally in the Pacific region. Customary systems are still very much prevalent in much of these fisheries (Aswani and Hamilton, 2004). This situation should certainly be seen as a positive initial building block on which to rely to make the adoption of the extended wantok easier, especially 
if information about the current status of the stock and the risk of depletion is shared and discussed openly with these fishing communities. The extended wantok system could also possibly reduce inequalities between fishers and lessen the risk of exclusion. Good fishers would then be respected by the community for their special role in this more redistributive system. This social recognition would further legitimate their activities through a form of social contract with the rest of the community. Cooperation might even ease tensions between fishers since only the most efficient fishers would be fishing, and they would exploit a higher biomass, which could thereby reduce the risk of 'race for fish' dynamics.

One the other hand, one might fear that this special role and responsibility may be instrumentalised by some of these fishers in an attempt to gain more power over the rest of the community -as it has been observed in other circumstances for fishers invited to participate in newly established co-management committees (Béné et al., 2009). In addition some would argue that cooperation mechanism such as the wantok may reduce inequality and redistributes fish catch within the entire community, but it also effectively dilutes the profit of these good fishers. Monsell-Davis (1993) for instance speaks about the wantok as "a system of poverty redistribution" because of the profit dilution problem combined with a low savings level and some sporadic sign of corruption (Haque, 2012).

The debate about the potential benefits and drawbacks of the wantok system is therefore still unsettled. What is clear however, is that the full cooperation requested under the extended wantok should not be considered as a magic bullet that can solve all and every over-exploitation problems. As we saw in this modelling exercise, resilience can be lost or non-existent even under a cooperative fishery if the resource-base on which the system relies is too low or badly affected by other factors such as pollution, climate change (Rasmussen et al., 2009; Jeisz and Burnett, 2009; Hoegh-Guldberg et al., 2009) or socio-economic instability (Duncan and Chand, 2002). 


\section{Conclusion}

The nexus between food security, poverty alleviation and resource conservation is one of the most challenging problems faced by many countries in the developing world (Adams, 2004; Sanderson, 2005; Rice, 2011; Bene et al., 2011). In the case of small state islands where natural resources are particularly limited and the dependence of the population on these resources particularly high, the problem becomes even more acute (Reenberg et al., 2008; Schwarz et al., 2010; Hardy et al., 2013). In the Pacific islands where poverty level remains important, population demography still high and the reef fisheries providing the main source of protein becoming under increasing pressure, finding the right balance to satisfy these constraints reveals particularly difficult (Aswani, 2002; Bell et al., 2009).

Using the Solomon Islands as a case study, and drawing on a multi-fleet dynamic fishery model, we explored in this paper various scenarios with the aim to assess the importance of the interaction between socio-economic and ecological dynamics, and to analyze more specifically the potential role that a local form of collective arrangements (called the wantok) could play in securing the viability of the system.

Numerical simulations using the dynamic model show that the wantok sytem has the potential to play a critical role in building the resilience of the local small-scale fishery and in strengthening the food security of the different members of the community. Combination of viable fishing strategies were identified which allow the preservation of the resource-base and at the same time enable the local fisheries to deliver their main social and economic functions. Our analysis shows that this positive outcome, which accounts for the growing demography of the local population and the impact of severe shocks on the resources, was made possible through the adoption of the extended wantok by these fishing communities.

Yet some challenge remains. The wantok has been implemented for many decades in the Solomon Islands fisheries, but its adaptation to the modern world is a critical issue. In particular the growing pressure for cash that is imposed by the increased marketization of the economy does represent a direct challenge for some of the more fundamental values 
that underpin this customary system. In that sense the long-term evolution of the whole fishery is still hard to anticipate. The lessons from the present analysis confirm, however, the importance of the wantok in maintaining the current socio-ecological viability of the whole system, and suggest that this importance may increase in the future as the pressure on the resource continues to increase.

\section{Acknowledgment}

This work was implemented with the financial support of the ANR (French National Research Agency) through the ADHOC program. The coordination and logistical support from WordFish's team in Gizo and Honiara are gratefully acknowledged.

\section{Bibliography}

Adams RJ (2004) Economic growth, inequality and poverty: estimating the growth elasticity of poverty. World Development 32: 1989-2014.

Alec H (2005) Gizo Marine Conservation Area Western Province, Solomon Islands Baseline Marine Survey. Tech. rep., World Wide Fund for Nature, Solomon Islands.

Armitage D, Béné C, Charles AT, Johnson D, Allison EH (2012) The Interplay of Well-being and Resilience in Applying a Social- Ecological Perspective. Ecology and Society 17.

Aswani S (2002) Assessing the effects of changing demographic and consumption patterns on sea tenure regimes in the Roviana Lagoon, Solomon Islands. AMBIO: A Journal of the Human Environment 31: 272-284.

Aswani S, Hamilton RJ (2004) Integrating indigenous ecological knowledge and customary sea tenure with marine and social science for conservation of bumphead parrotfish (Bol- 
bometopon muricatum) in the Roviana Lagoon, Solomon Islands. Environmental Conservation 31: $69-83$.

Aswani S, Sabetian A (2009) Implications of Urbanization for Artisanal Parrotfish Fisheries in the Western Solomon Islands. Conservation Biology 24: 520-530.

Bahadur AV, Ibrahim M, Tanner T (2010) The resilience renaissance? Unpacking of resilience for tackling climate change and disasters. Tech. Rep. 1, IDS, Brighton.

Bell JD, Kronen M, Vunisea A, Nash W, Keeble G, et al. (2009) Planning the use of sh for food security in the Pacic. Marine Policy 33: 64-76.

Béné C, Belal E, Baba MO, Ovie S, Raji A, et al. (2009) Power struggle, dispute and alliance over local resources: analyzing 'democratic' decentralization of natural resource through the lenses of Africa inland fisheries. World Development 37: 1935-1950.

Béné C, Doyen L, Gabay D (2001) A viability analysis for a bio-economic model. Ecological Economics 36: 385-396.

Bene C, Evans L, Mills D, Ovie S, Raji A, et al. (2011) Testing resilience thinking in a poverty context: Experience from the Niger River basin. Global Environmental Change 21: $1173-1184$.

Béné C, Godfrey-Wood R, Newsham A, Davies M (2012) Resilience: New utopia or new tyranny? - Reflection about the potentials and limits of the concept of resilience in relation to vulnerability reduction programmes. Tech. Rep. 405, Institute of Development Studies, Brighton.

Berkes F, Colding J, Folke C (2003) Navigating social-ecological systems: Building resilience for complexity and change. Cambridge, UK: Cambridge University Press,.

Borkman T (1999) Understanding Self-Help/Mutual Aid: Experiential Learning in the Commons. Rutgers University Press. 
Botsford LW, Castilla JC, Peterson CH (1997) The Management of Fisheries and Marine Ecosystems. Science 277: 509-515.

Brewer TD, Cinner JE, Fisher R, Green A, Wilson SK (2012) Market access, population density and socioeconomic development explain diversity and functional group biomass of coral reef sh assemblages. Global Environmental Change 22: 399-406.

Browne C, Scott DA (1990) Economic Development in Seven Pacific Islands Countries. washington D.C: International Monetary Fund.

Carr L, Medelsohn R (2003) Valuing Coral Reefs: A Travel Cost Analysis of the Great Barrier Reef. AMBIO: A Journal of the Human Environment 32: 353-357.

CIA (2001) The World Factbook.

Cinner JE (2005) Socioeconomic factors influencing customary marine tenure in the IndoPacific. Ecology and Society 10: 1-14.

Cinner JE (2009) Migration and coastal resource use in Papua New Guinea. Ocean \& Coastal Management 52: 411-416.

Clark CW (1990) Mathematical Bioeconomics. New York: J. Wiley.

Crossland J, Philipson PW (1993) The Rural Fishing Enterprise Project in Solomon Islands: Fish Market and Marketing Study. Tech. rep., Delegation of the Commission of the European Communities in Solomon Islands, Honiara, Solomon Islands.

Dalzell P, Adams TJ (1996) Sustainability and management of reef fisheries in the Pacific Islands. Tech. rep., SPC, Noumea, New Caledonia.

Dalzell P, Adams TJ, Polunin NVC (1996) Coastal fisheries in the Pacific Islands. Oceanography and Marine Biology: an Annual Review 34: 395-531. 
Deffuant G, Gilbert N (2011) Viability and Resilience of Complex Systems, Concepts, Methods and Case Studies from Ecology and Society. Boston/Dordrecht/London: Kluwer Academic Publishers.

Dignan C, Burlingame B, Kumar S, Aalbersberg W (2004) The Pacific Islands food composition tables. Rome: Food and Agriculture Organization of the United Nations.

Duncan R, Chand S (2002) The Economics of the Arc of Instability. Asian-Pacific Economic Literature 16.

Faanunu K (n.d.) Christian Fellowship Church Reforestation: A change in customary land tenure in the Solomon Islands? Master's thesis, Unpublished.

Feinberg R (1996) Outer Islanders and Urban Resettlement in the Salomon Islands: The Case of Anutans on Guadalcanal. Journal de la Société des Océanistes 103: 207-217.

Frankenberger T, Nelson S (2013) Background Paper for the Expert Consultation on Resilience Measurement for Food Security. Tech. rep., TANGO International.

Gibson J, Brown M (2006) Are the Pacific Island Economies Growth Failures? Tech. Rep. Working Paper 3, Department of Economics, University of Waikato, Private Bag 3105, Hamilton, New Zealand.

Gillett R (2010) Marine shery resources of the Pacic Islands. Tech. rep., FAO, Rome.

Gordon LN (2011) The Wantok System as a Socio-economic and Political Network in Melanesia. OMNES: The Journal of Multicultural Society 2: 31-35.

Green A, Lokani P, Atu W, Ramohia P, Thomas P, et al. (2006) Solomon Islands Marine Assessment: Technical report of survey conducted May 13 to June 17, 2004. Tech. Rep. 106, TNC Pacific Island Countries.

Halpern BS, Walbridge S, Selkoe KA, Kappel CV, Micheli F, et al. (2008) A Global Map of Human Impact on Marine Ecosystems. Science 319: 948-952. 
Handmer J, Choong W (2009) Resilience: wantoks, transnational traders and global politics, pp. 208-219. Damien grenfell and paul james ed., London, UK: Routledge.

Hanson FB, Ryan D (1998) Optimal Harvesting with Both Population and Price Dynamics. Mathematical Biosciences 148: 129-146.

Haque TA (2012) The Influence of Culture on Economic Development in Solomon Islands, A Political-Economy Perspective. SSGM Discussion Paper 1.

Hardy PY, Béné C, Doyen L, Schwarz AM (2013) Food security versus environment conservation: A case study of solomon islands' small-scale fisheries. Environmental Development p. in press.

Hoegh-Guldberg O, Hoegh-Guldberg H, Veron JEN, Green A, Gomez ED, et al. (2009) The Coral Triangle and Climate Change: Ecosystems, People and Societies at Risk. Tech. rep., WWF, Australia, Brisbane.

Hviding E (1996) Guardians of Marovo Lagoon: practice, place and politics in maritime melanesia. Pacific Islands Monograph Series, University of Hawai'i Press.

Jeisz S, Burnett BJ (2009) Climate Change and Biodiversity in Melanesia. Tech. Rep. 42, Bishop Museum.

Johannes RE (1981) Words of the lagoon: fishing and marine lore in the palau district of micronesia. Berkeley and Los Angeles, California: University of Californai Press.

Kinch J, Mesia P, Kere N, Manioli J, Bulehite K (2005) Socioeconomic baseline study: Eastern Marovo Lagoon, Solomon Islands. Tech. Rep. 35, IWP-Pacific.

Kramer DB (2007) Adaptive Harvesting in a Multiple-Species Coral-Reef Food Web. Ecology and Society 13.

Kronen M (2004) Fishing for fortunes? A socio-economic assessment of Tonga's artisanal fisheries. Fisheries Research 70: 121-134. 
Kronen M (2007) Monetary and non-monetary values of small-scale fisheries in Pacific Island countries. SPC Women in Fisheries Information Bulletin 16: 12.

Kronen M, Sauni S, Veitayaki J (2008) Reef and lagoon fish prices: The transition from traditional to cash-based economic systems - Case studies from the Pacific Islands. In: Nielsen, J and Dodson, JJ and Friedland, K and Hamon, TR and Musick, J and Verspoor, E, editor, Reconciling Fisheries with Conservation, Vols I and II, vol. 49 of Amecrican Fisheries Socitey Symposium, pp. 609-626, Amer Fisheries Soc.

Kropotkin P (2009 [1904]) Mutual Aid, A Factor of Evolution. New York: Cosimo, Inc.

LaFranchi C (1999) Islands Adrift? Comparing Industrial and Small-Scale Economic Options for Marovo Lagoon Region of the Solomon Islands. Tech. rep., GreenPeace, Suva, Fiji.

Manyena B (2006) The concept of resilience revisited. Disasters 30.

Marshall D (1963) Poor Man, Rich Man, Big-Man, Chief: Political Types in Melanesia and Polynesia. Comparative Studies in Society and History 5: 285-303.

Martin S (2005) La Résilience dans les Modèles de Systèmes Ecologiques et Sociaux. Ph.D. thesis, Ecole Normale Superieure de Cachan.

Masu R, Vave-Karamui A (2012) State of the Coral Triangle Report, Solomon Islands. Tech. rep., Coral Triangle Initiative, Cairns, Australia.

Molea T, Vuki V (2008) Subsistence fishing and fish consumption patterns of the saltwater people of Lau Lagoon, Malaita, Solomon Islands: A case study of Funaafou and Niuleni Islanders. SPC Women in Fisheries Information Bulletin 18.

Monsell-Davis M (1993) Urban Exchange: Safety-Net Or Disincentive? Wantoks and relatives in the urban Pacific. Canberra Anthropology 16: 45-66.

Mora C (2008) A clear human footprint in the coral reefs of the Caribbean. Proceedings of the Royal Society B: Biological Sciences 275: 767-773. 
National Statistic Office N (1999) 1999 Census Cross - Tabulations. Tech. rep., Solomon Islands Government, pacifiweb.org.

National Statistic Office N (2008) Solomon Islands projected population by province 19992014. SPC releases latest Pacific population data.

Oliver D (1989) Native Culture of the Pacific Islands. Hawaii: University of Hawaii Press.

Oreihaka A, Ramohia P (1994) The state of subsistence and commercial fisheries in Solomon Islands. Tech. rep., Fisheries Division. Department of Agriculture and Fisheries, Honiara, Solomon Islands.

Oru M (2011) The evolution of accounting in the Solomon Islands: An interpretative study on the impact of culture. Auckland University of Technology.

Pereau JC, Doyen L (2012) Sustainable coalitions in the commons. Mathematical Social Sciences 63: 57-64.

Rasmussen K, May W, Birk T, Mataki M, Metz O, et al. (2009) Climate change on three Polynesian outliers in the Solomon Islands: Impacts, vulnerability and adaptation. Danish Journal of Geography 109: 1-13.

Reenberg A, Birch-Thomsen T, Mertz O, Fog B, Christiansen S (2008) Adaptation of Human Coping Strategies in a Small Island Society in the SW Pacific - 50 Years of Change in the Coupled Human Environment System on Bellona, Solomon Islands. Human Ecology pp. $807-819$.

Rice J (2011) Managing fisheries well: delivering the promises of an ecosystem approach. Fish and Fisheries 12: 209-231.

Russell T (1948.) The Culture of Marovo, British Solomon Islands. Journal of the Polynesian Society 57: 306-329. 
Sabetian A (2010) Parrotfish fisheries and population dynamics: a case-study from Solomon Islands. Ph.D. thesis, James Cook University.

Sadovy Y (2005) Trouble on the reef: the imperative for managing vulnerable and valuable sheries. Fish and Fisheries 6: 167-185.

Sampson DB (1992) Fishing Technology and Fleet Dynamics: Predictions from a Bioeconomic Model. Marine Resource Economics, 7: 37-38.

Sanderson S (2005) Poverty and Conservation: The New Centurys "Peasant Question?. World Development 33: 323-332.

Scheffer M (2009) Critical Transitions in Nature and Society. Princeton Studies in Complexity, Princeton University Press.

Scheffer M (2011) Foreseeing tipping points. Nature 467: 411-412.

Schwarz A, Béné C, Bennett G, Boso D, Hilly Z, et al. (2010) Vulnerability and resilience of remote rural communities to shocks and global changes: empirical analysis from Solomon Islands. Global Environmental Change 21: 1128-1140.

Schwarz AM, Ramofafia C, Bennett G, Notere D, Tewfik A, et al. (2007) After the earthquake: An assessment of the impact of the earthquake and tsunami on fisheries-related livelihoods in coastal communities of Western Province, Solomon Islands. Tech. rep., WorldFish Center, World Wide Fund, Gizo, Solomon Islands.

Sheppard P, Walter R (2006) A revised model of Solomon Islands culture history. Journal of the Polynesian Society 115: 47-76.

Spalding MD, Ravilious C, Green EP (2001) World Atlas of Coral Reefs. Berkeley: Univ. California Press. 
Sunderlin WD (1994) Beyond Malthusian overfishing: The importance of structural and non-demographic factors. SPC Traditional Marine Resource Management and Knowledge Information Bulletin 4: 2-6.

Weeratunge N, et al. (2011) Planning the fish for Food Security in Solomon Islands. Tech. rep., United States Agency for International Development.

White GM (1991) Identity Through History, living story in a Solomon Islands Society. Cambridge University Press.

Yari M (2003/04) Beyond "Subsidence Affluence: Poverty in Pacific Island Countries. Bulletin on Asia-Pacific Perspectives . 


\section{Appendix}

\subsection{Optimal strategies}

We aim at solving optimality problems under constraints introduced in (5) both in cooperative and non cooperative frameworks. A Lagrangian method involving Kuhn and Tucker multipliers is used to compute the optimal effort in both cases.

Non cooperation: Within the non cooperation framework, the Lagrangian accounting for the individual cash criterion and subsistence constraint is defined as follows:

$$
\mathcal{L}\left(e_{i}, \lambda\right)=q_{i} e_{i} B p-c_{0}-c_{1, i} e_{i}-c_{2} e_{i}^{2}+\lambda\left(q_{i} e_{i} B-H_{\lim }\right)
$$

The first order conditions for the optimal effort $e_{i}^{n c}(t)$ are given by :

$$
0=\frac{\partial \mathcal{L}}{\partial e_{i}}=q_{i} B p-c_{1, i}-2 c_{2} e_{i}+\lambda^{n c} q_{i} B
$$

which leads to:

$$
e_{i}^{n c}=\frac{\left(\lambda^{n c}+p\right) q_{i} B-c_{1, i}}{2 c_{2}}
$$

Moreover the optimal multipliers is known to be positive $\lambda^{n c} \geq 0$ and the slackness conditions holds true with

$$
\lambda^{n c}\left(q_{i} e_{i} B-H_{\lim }\right)=0
$$

We can distinguish between two cases

- If $\lambda^{n c}=0$, the subsistence constraint is inactive and we deduce

$$
e_{i}^{n c}=\frac{q_{i} B p-c_{1, i}}{2 c_{2}}
$$


- If $\lambda^{n c} \neq 0$, the constraint is active $q_{i} e_{i}^{n c} B=H_{\text {lim }}$ and we obtain

$$
e_{i}^{n c}=\frac{H_{\lim }}{q_{i} B}
$$

Therefore, we can write the non cooperative strategy as follows

$$
e_{i}^{n c}(t, B(t))=\max \left(\frac{p q_{i} B(t)-c_{1, i}}{2 c_{2}}, \frac{H_{\lim }}{q_{i} B}\right)
$$

Cooperation: Within the non cooperation framework, the Lagrangian accounting for the individual cash criterion and subsistence constraint is defined as follows:

$$
\mathcal{L}\left(e_{1}, \ldots, e_{N(t)}, \lambda\right)=\sum_{i=1}^{N(t)}\left(p q_{i} e_{i} B-c_{0}-c_{1, i} e_{i}-c_{2} e_{i}^{2}\right)+\lambda\left(\sum_{i=1}^{N(t)}\left(q_{i} e_{i} B-H_{\lim }\right)\right)
$$

The first order conditions for the optimal effort $e_{i}^{c}(t)$ of every agent are again given by :

$$
0=\frac{\partial \mathcal{L}}{\partial e_{i}}=p q_{i} B-c_{1, i}-2 c_{2} e_{i}+\lambda^{c} q_{i} B
$$

which leads to

$$
e_{i}^{c}=\frac{\left(p+\lambda^{c}\right) q_{i} B-c_{1, i}}{2 c_{2}}
$$

Moreover as the optimal efforts need to remain positive, we write

$$
e_{i}^{c}=\max \left(0, \frac{\left(p+\lambda^{c}\right) q_{i} B-c_{1, i}}{2 c_{2}}\right)
$$

Furthermore, the optimal multipliers is known to be positive $\lambda^{c} \geq 0$ and the slackness conditions holds true with

$$
\lambda^{c} \sum_{i}^{N(t)}\left(q_{i} e_{i} B-H_{\lim }\right)=0
$$

We can distinguish between two cases

- If $\lambda^{c}=0$, the global subsistence constraint is inactive and we deduce similarly to 
cooperative case

$$
e_{i}^{c}=\frac{q_{i} B p-c_{1, i}}{2 c_{2}}
$$

- If $\lambda^{c} \neq 0$, the constraint is active $\sum_{i} q_{i} e_{i}^{n c} B=N(t) H_{\text {lim }}$ and we obtain

$$
\sum_{i \in A(t)} B q_{i} \frac{q_{i} B p-c_{1, i}+\lambda q_{i} B}{2 c_{2}}=N(t) H_{\lim }
$$

with $A(t)$ is the set of active agents in the sense of fishermen with a positive optimal effort $e_{i}^{\star}=\max e_{i}>0$ which imply

$$
(p+\lambda) B(t) q_{i}-c_{1, i}>0
$$

Therefore $\mathrm{A}(\mathrm{t})=$

$$
\left\{\exists i^{\star}, q_{i^{\star}} B(t)\left(\frac{N(t) H_{\lim } 2 c_{2}+\sum_{j=1}^{i^{\star}} c_{1, j} q_{j}}{\sum_{j=1}^{i^{\star}} q_{j}^{2}}\right)-c_{1, i} \geq 0\right\}
$$

We deduce that

$$
\lambda=\frac{1}{B^{2} \sum_{i \in A(t)} q_{i}^{2}}\left(2 l c_{2} H_{\lim }-p B^{2} \sum_{i \in A(t)} q_{i}^{2}+B \sum_{i \in A(t)} q_{i} c_{1, i}\right)
$$

Setting

$$
\delta=\sum_{i \in A(t)} q_{i}^{*^{2}}, \gamma=\sum_{i \in A(t)} q_{i}^{*} c_{1, i}
$$

we derive the optimal controls when the subsistence constraint is binding

$$
e_{i}^{c}=\frac{1}{2 c_{2}}\left(\frac{2 N(t) c_{2} q_{i} H_{\mathrm{lim}}}{B \delta}+q_{i} \frac{\gamma}{\delta}-c_{1, i}\right)
$$


Mixing the two cases, we obtain the feedback control law

$$
e_{i}^{c}(t, B(t))=\max \left(\frac{p q_{i} B(t)-c_{1, i}}{c_{2}}, \frac{1}{2 c_{2}}\left(\frac{2 N(t) c_{2} q_{i} H_{\mathrm{lim}}}{B \delta}+q_{i} \frac{\gamma}{\delta}-c_{1, i}\right)\right)
$$

The two effort expression (14) and (20) are similar then $e_{i}^{n c}=e_{i}^{c}$ for $\lambda=0$. The interesting features will come from the second expression of the effort maximization. This expression differs in both case and drive the potential difference depending on the number of active agents.

\subsection{Calibration}

The different parameters used in the second model are taken from the literature related to the Western Region in Solomon Islands and from the surveys conducted during two weeks (from the 2 to the 6 of May and from the 16 to the 20 of May) in the Gizo Market. The following table 3 inform the estimated profit fishers would think of at the begining of the market, the price they think they will get, their catch of the day, their effort of the day and their estimated cost of the day we have divided by the effort. The average linear costs are composed of: an ice-block (25 \$ SBD) in Gizo, hooks and lines (arround 15 \$ SBD which last at least three weeks or $5 \$$ SBD per week) and a liter of gasoline per hour with 17 SB a liter in Gizo (2011 prices). The sum of costs divided by the average effort of 8 hours equals to:

$$
\frac{25+5+17 * 7}{7}=21
$$

Therefore the fishers have good estimation of the linear cost whereas they under estimate the average price compare to the value of Brewer et al. (2012) who gave $10 \$$ SB for this same market.

Those data when averaged are used to calculate the quadratic linear cost thanks to the equation (22), see below: 


\begin{tabular}{|c||c|c|c|c|c|}
\hline Community & Profit* $^{*}$ & Price* $^{*}$ & Effort & Capture & Costs* $^{*}$ \\
\hline Net user & 450 & 7.5 & 4 & 100 & 200 \\
\cline { 2 - 6 } $\begin{array}{c}\text { Spear user } \\
\text { Line user (1/2 day) }\end{array}$ & 300 & 9 & 9.5 & 110 & 350 \\
\cline { 2 - 6 } Line user (day/night) & 100 & 8 & 7 & 10 & 10 \\
\cline { 2 - 6 } Average & 75 & 9.5 & 12 & 20 & 40 \\
\cline { 2 - 6 } & 218.75 & 8.125 & 8 & 60 & 21 \\
\hline
\end{tabular}

Table 2: Market surveys compilation by community, profit, costs and market price are expresed in $\$ S B$, the effort in hour per day per fisher and the catch per $\mathrm{kg}$.

$$
c_{2}=\frac{\bar{H} \bar{p}-\overline{c_{1}} \bar{e}-\bar{\pi}}{\bar{e}^{2}}=2
$$

The table below summarize all the paramters.

\begin{tabular}{|c|c|c||c|}
\hline Name & Symbol & Value & Reference \\
\hline intrinsic growth & $r$ & 0.041 & (Kramer, 2007) \\
\cline { 2 - 4 } caring capacity $(\mathrm{Kg})$ & $K$ & 2875000 & (Green et al., 2006) \\
\cline { 2 - 4 } biomass $(\mathrm{Kg})$ & $B$ & 307050 & (Green et al., 2006) \\
\cline { 2 - 4 } area $\left(\mathrm{km}^{2}\right)$ & & 5.75 & (Spalding et al., 2001) \\
price $(\$ \mathrm{SB})$ & $p$ & 8.5 & (Kinch et al., 2005) \\
\cline { 2 - 4 } linear cost $(\$ S B)$ & $c_{1, i}$ & 21 & Table (3) \\
\cline { 2 - 4 } quadratic cost $(\$ S B)$ & $c_{2}$ & 2.2 & Table (3) \\
\cline { 2 - 4 } demographic rate & $d$ & 0.0214 & (National Statistic Office, 2008) \\
\cline { 2 - 4 } & & &
\end{tabular}

Table 3: List of parameters and values used in the model. 


\title{
Cahiers du GREThA Working papers of GREThA
}

\author{
GREThA UMR CNRS 5113 \\ Université Montesquieu Bordeaux IV \\ Avenue Léon Duguit \\ 33608 PESSAC - FRANCE \\ Tel : +33 (0)5.56.84.25.75 \\ Fax : $+33(0) 5.56 .84 .86 .47$ \\ http://gretha.u-bordeaux4.fr/
}

\begin{abstract}
Cahiers du GREThA (derniers numéros - last issues)
2013-07 : LASKOWSKI Natacha, Optimal allocation of wetlands: Study on conflict between agriculture and fishery

2013-08 : OUEDRAOGO Boukary, Acceptation et usages éducatifs des Technologies de I'Information et de la Communication (TIC) par les professeurs de I'Université de Ouagadougou (Burkina Faso) : une application du modèle TUAUT

2013-09: FRIGANT Vincent, Une comparaison de l'internationalisation des chaînes d'approvisionnement automobiles allemande et française

2013-10 : MOYES Patrick, Rearrangements and Sequential Rank Order Dominance

2013-11 : BECUWE Stéphane, BLANCHETON Bertrand, La place du vin dans les échanges internationaux de la France pendant la première mondialisation

2013-12 : LAVIGNE Stéphanie, NICET-CHENAF Dalila, DUPUY Claude, Where do "impatient" mutual funds invest? A special attraction for large proximate markets and companies with strategic investors

2013-13 : CARAYOL Nicolas, STERZI Valerio, Signaling and the Ownership of Academic Patents

2013-14 : PASTUREAU Guillaume, De l'usage social aux pratiques marchandes de l'argent. Une brève histoire des origines du microcrédit social

2013-15 : CHARLES Léo, Why did Switzerland succeed? An analysis of Swiss specializations (18851905)

2013-16 : PASTUREAU Guillaume, Du Mont-de-Piété à la Grameen Bank: la finance sociale à travers le temps et l'espace. Essai sur une cohérence institutionnelle et une diversité des pratiques

2013-17 : BECUWE Stéphane, BLANCHETON Bertrand, CHARLES Léo, First globalization: why did France miss the boat?

2013-18 : HARDY P.H., BENE C., DOYEN L., PEREAU J. C., MILLS D., Viability and resilience of smallscale fisheries through cooperative arrangements
\end{abstract}

La coordination scientifique des Cahiers du GREThA est assurée par Sylvie FERRARI et Vincent FRIGANT. La mise en page est assurée par Anne-Laure MERLETTE. 